\title{
Aleitamento materno: o desafio de compreender a vivência
}

\section{Breastfeeding: the challenge to understand the experience}

Raquel Maria Amaral ARAÚJO'

João Aprígio Guerra de ALMEIDA 2,3

\section{RES U M O}

Este trabalho visa contribuir para uma reflexão sobre o papel dos profissionais de saúde perante a mulher que vivencia o processo da amamentação. Foram utilizadas publicações acerca do tema, oriundas de revistas científicas, teses, dissertações, livros técnicos e publicações de organismos nacionais e internacionais. Essa reflexão parte das evidências científicas acerca das demandas da assistência em amamentação, no que se refere à vivência da mulher nesse processo. São apontadas as limitações dos profissionais de saúde, inclusive do nutricionista, diante das exigências no assistir em amamentação. Evidenciou-se, neste estudo, a necessidade da capacitação dos profissionais de saúde para atuar na assistência em amamentação, numa abordagem que ultrapasse as fronteiras do biológico, compreendendo a nutriz em todas as dimensões do ser mulher. Da mesma forma, urge que se amplie o debate, ainda escasso, sobre a atuação do nutricionista na assistência à amamentação.

Termos de indexação: aleitamento materno; assistência à saúde; educação alimentar e nutricional; papel profissional.

\section{A B S T R A C T}

This work aims to contribute to a reflection on the role of health professionals regarding women who breastfeed. Publications from scientific journals, theses, dissertations, textbooks and papers from national and international organizations were consulted. This reflection originates from the scientific evidences on the requirements of breastfeeding assistance regarding what the woman experiences during this process. The limitations of health professionals, including nutritionists, are pointed out, in respect to the requirements of providing breastfeeding assistance. This study evidenced the need to train health professionals to provide breastfeeding assistance that goes beyond the biological aspect, encompassing all facets of womanhood. In the same manner, we urge that the debate on the nutritionist's role in breastfeeding assistance be expanded as it is still scarce.

Indexing terms: breast feeding; delivery of health care; food and nutrition education; professional role.

\footnotetext{
${ }^{1}$ Universidade Federal de Viçosa, Departamento de Nutrição e Saúde. Av. P.H. Rolfs, s/n., 36571-000, Viçosa, MG, Brasil. Correspondência para/Correspondence to: R.M.A. ARAÚJO. E-mail:<raraujo@ufv.br>.

2 Instituto Fernandes Figueira, Cursos de Mestrado e Doutorado em Saúde da Mulher e da Criança. Rio de Janeiro, RJ, Brasil.

3 Fundação Oswaldo Cruz, Instituto Fernandes Figueira, Bancos de Leite Humano. Rio de Janeiro, RJ, Brasil.
} 


\section{N T R O D U Ç Ã O}

A ciência é unânime ao reconhecer o leite materno como fonte segura de nutrição para o humano ${ }^{1,2}$ no início de vida, cujos benefícios ecoam para a idade adulta. Além de nutrir, atendendo às especificidades fisiológicas do lactente, o seu caráter funcional assegura proteção imunológica e função moduladora³ .

Além da dimensão biológica, na prática da amamentação há inúmeros fatores, com diferentes efeitos sobre a dimensão social e a aparelhagem psíquica dos atores diretamente envolvidos.

Na perspectiva da política pública de saúde, em face dos benefícios que congrega, a amamentação exclusiva até os seis meses de vida da criança e a manutenção do aleitamento materno até os dois anos de idade ou mais, configuraram-se em recomendação oficial ${ }^{4}$. Este intento impulsionou a realização de inúmeros estudos em busca de estratégias eficazes para responder à proposição estatal. De maneira geral, os resultados são unânimes em apontar o desempenho do profissional de saúde como elemento básico para o sucesso da amamentação ${ }^{5-8}$.

Os serviços e profissionais de saúde têm sido alvo de discussões sobre atitudes e práticas diante da promoção da amamentação. Constantemente, ambos são responsabilizados pelo sucesso dessa prática, cuja atuação na promoção, informação e apoio às mulheres estende-se da atenção ao pré-natal, ao parto, puerpério imediato e puericultura ${ }^{5-8}$.

A valoração dos profissionais de saúde é realçada em documento da $55^{a}$ Assembléia Mundial de Saúde9, que aponta a necessidade de as mães receberem apoio especializado, ou seja, de alguém capaz de ajudá-las a iniciar e manter práticas apropriadas de alimentação da criança, bem como prevenir e ajudar a superar dificuldades.

Neste cenário complexo insere-se o nutricionista, formado para cuidar da alimentação do humano nas diferentes fases do ciclo de vida e lidar com os reflexos dessa prática na saúde coletiva. Considerando a supremacia do leite materno na alimentação inicial da criança, a amamentação torna-se, portanto, objeto inerente à orientação nutricional. Assim, esse profissional configura-se em um importante protagonista na viabilização das recomendações oficiais sobre a amamentação.

Em atenção à importância da atuação dos profissionais de saúde na promoção do aleitamento materno, faz-se necessário discutir sobre as demandas da assistência em amamentação e a prática realizada por tais atores.

Diante dessa perspectiva, objetiva-se, neste artigo, contribuir para uma reflexão sobre o papel dos profissionais de saúde, entre os quais se inclui o nutricionista, diante das complexas questões que permeiam a amamentação.

\section{A vivência em amamentação}

Amamentar é o ato de a criança obter o leite materno sugando as mamas, ou a oferta, pela mãe à criança, da mama e seu leite. À luz dos referenciais teóricos da fisiologia da lactação, praticamente, todas as mulheres têm possibilidades fisiológicas de amamentar ${ }^{3}$, porém, esse potencial inato não assegura a ocorrência da amamentação. O desmame precoce, apesar da melhora nos seus índices no Brasil, ainda continua sendo uma realidade ${ }^{10-12}$, dificultando a prática do aleitamento materno exclusivo até os seis meses, preconizada pela Organização Mundial de Saúde.

Muitas mulheres, embora considerem o leite materno a melhor opção alimentar para a criança, não amamentam ${ }^{13}$. Mesmo aquelas que se submetem à rotina assistencial, estabelecida pela política estatal como base para o êxito na amamentação, costumam desmamar seus filhos antes do quarto mês de vida ${ }^{14}$. Apesar de as mães valorizarem o leite materno, não se sentem seguras a ponto de adotá-lo como único alimento durante o período em que ele é indicado ${ }^{15}$. Ainda 
que a biologia materna concorra para a lactação, ou seja, o seu arcabouço fisiológico esteja apto para a produção do leite, a amamentação pode não ocorrer.

Na busca de explicações para essa tendência ao desmame, vários estudos foram realizados. As mais freqüentes conclusões sobre os fatores que concorrem para essa situação referem-se a informações recebidas sobre amamentação, trabalho fora do lar e dificuldades encontradas na vivência da amamentação, sendo comuns as alegações do "leite fraco", "pouco leite" ou que o "leite secou"16-19.

Esses estudos muito têm contribuído para dissipar a nuvem de incertezas quanto aos elementos envolvidos no processo de amamentação, e novos caminhos de investigação têm sido abertos para que se conheça esse fenômeno a partir da perspectiva da mulher. Essas várias possibilidades de apreender a realidade da mulher lactante são oriundas do instrumental teórico e metodológico da pesquisa qualitativa, que possibilita caminhar para o universo de significações, motivos, aspirações, atitudes, crenças e valores ${ }^{20}$.

As mulheres, ao se referirem à amamentação, comumente, demonstram essa prática carregada de aspectos positivos e negativos. $O$ esforço físico da mulher ${ }^{21}$, a fadiga ${ }^{22}$, a limitação no desempenho de suas funções ${ }^{21,23}$, incluindo o cuidado com o seu próprio corpo ${ }^{24}$, e a difícil conciliação entre o exercício da sexualidade e a amamentação ${ }^{23}$ são vistos de forma negativa. Elas também expressam o sentimento de solidão e isolamento, e precisam de apoio para a consecução da amamentação, demonstrando a necessidade de auxílio externo ${ }^{22,14}$. Já o contato físico é prazeroso para a mulher, uma vez que possibilita maior ligação afetiva entre ela e a criança21.

Outra constatação, na fala das mulheres, é a ambigüidade entre o querer e o poder amamentar ${ }^{14}$. Essa observação aponta para a dificuldade da mulher na tomada de decisão sobre a amamentação, provavelmente, em virtude dos múltiplos papéis que desempenha e da necessidade de responder ao imputado dever materno de amamentar. A mulher sente-se cobrada pela sociedade, que valoriza a maternidade e vê a prática de amamentar como uma virtude natural, semantizada, um dom divino, puro e universal 24,25. Dessa forma, a mulher anseia por cumprir, como mãe, as tarefas da maternidade e realizar a amamentação. Porém, nem sempre essas tarefas são condizentes com o seu cotidiano de mulhermãe-profissional.

Arantes $^{21}$, ao estudar o significado da amamentação para a mulher que amamenta, também verificou a ambivalência de sentimentos, em que, a priori, a mulher percebe a amamentação como algo bom e, num segundo momento, ela reflete sobre suas conseqüências positivas e negativas. A autora, apoiando-se no discurso de Badinter ${ }^{26}$ sobre o mito do amor materno, analisa o primeiro momento, em que a amamentação é colocada do ponto de vista positivo, como resultante da relação direta que há entre o ato da amamentação e o amor materno. Badinter ${ }^{26}$ assinala que, ainda hoje, muitos vêem o amor da mãe por seu filho como instintivo, natural e inevitável, no qual a função materna é evocada como uma vocação ou sacrifício, ou seja, a sociedade cobra da mulher o amor materno. Conseqüentemente, em seus relatos, muitas mulheres se posicionam socioculturalmente em conformidade com a concepção da sociedade sobre o processo da amamentação. Como bem assinala Silva ${ }^{27}$, o aleitamento materno é um comportamento social mutável, ou seja, pode variar conforme as épocas e os costumes, e a sua prática ou a recusa, raramente, é um ato individualmente consciente, estando preso à aprovação do seu grupo social. Segundo esse mesmo autor, na concepção social, o aleitamento materno pode configurar-se como fardo ou desejo.

Nakano \& Mamede ${ }^{28}$ buscaram apreender os significados que as mulheres atribuem às vivências e demandas na prática do aleitamento materno, sob o aspecto da identidade feminina. Essas autoras identificaram movimentos de acomodação e resistência das mulheres frente a essa prática, os quais expressam a influência do modelo cultural de mãe, que Ihes outorga este 
papel considerando a sua "natureza" hábil à maternagem.

Da mesma forma que o senso comum influencia a percepção da mulher sobre a amamentação, a cultura científica também condiciona a sua conduta perante a amamentação. Isso é evidenciado por Nakano ${ }^{25}$, em seu estudo sobre as vivências da amamentação para um grupo de mulheres: "As mulheres reafirmam o desejo idealizado de amamentar, para "dar o melhor para o seu filho", respaldando-se no discurso oficial cientificamente instituído [...] Para elas, é preciso ter (leite, experiência, conhecimento) para poder amamentar" (p.111).

Apesar de a tomada de decisão pela amamentação ser complexa, algumas mulheres conseguem vencer os obstáculos e avançar nesse processo com maior tranqüilidade. Machado ${ }^{29}$, ao tentar conhecer como se desenvolve a tomada de decisão pela amamentação, por mulheres que o fizeram até os seis meses, observou que há uma motivação interior que as ajuda a superar as opiniões contrárias, ou seja, algo que as faz sentir seguras quando decidem amamentar seus filhos.

Dado que a escolha pela amamentação se desenvolve dentro de um contexto sociocultural, a sua prática é, portanto, influenciada pela cultura, pelas crenças e tabus próprios daquele contexto. Exemplo clássico da influência cultural, relacionada às crenças e aos tabus sobre a produção do leite, é o uso dos lactogogos ${ }^{30}$, alimentos estimulantes da produção láctea ${ }^{31}$. Segundo Moreira ${ }^{23}$, durante o período lactacional, a mulher valoriza a importância da alimentação para uma boa produção láctea e incorpora valores culturais na definição de sua dieta.

Outro aspecto apontado pelas mulheres refere-se à sua experiência em amamentar. Algumas delas valorizam a experiência anterior ou a oportunidade de acompanhar uma lactante ${ }^{32}$. Porém, é preciso considerar que essa experiência, nem sempre, irá resultar em um estímulo para a prática da amamentação, pois a mulher poderá vivenciar uma experiência, sua ou de uma outra pessoa, com significado negativo e isso prejudicar, posteriormente, a sua decisão em amamentar. Rezende et al. ${ }^{33}$ exemplificam: "[...] ver mulheres amamentando às escondidas - longe do público - pode transmitir à criança a idéia de que a amamentação é um evento íntimo talvez até vergonhoso [...]" (p.235). A questão da experiência anterior tem grande significado na assistência a primíparas que, devido ao fato de nunca terem tido filho, não passaram pela experiência da amamentação. Entretanto, é importante considerar a observação feita por Arantes ${ }^{21}$ de que a prática da amamentação é única a cada filho gerado, ou seja, é uma experiência que a mãe vivencia de forma diferente no primeiro filho, no segundo e assim por diante.

Com base nas pesquisas realizadas no âmbito da amamentação e, em especial, aquelas que focalizaram a vivência de amamentar do ponto de vista da nutriz, é possível compreender que a amamentação apresenta aspectos plurais na sua prática. A sua questão não é somente biológica, mas também, histórica, social e cultural.

Conseqüentemente, a amamentação é hoje discutida como uma categoria híbrida, construída pelos elementos da natureza e da cultura, uma vez que, além de ser biologicamente determinada, é socioculturalmente condicionada ${ }^{34}$.

Ao abordar o tema, a referência não deve se limitar ao fornecimento de nutrientes e seus demais bioelementos, como pondera Almeida ${ }^{34}$.

Os clássicos parâmetros nutricionais, químicos, físicos, imunológicos, microbiológicos e fisiológicos não podem ficar circunscritos ao microcosmo dos fenômenos - embora importantes - que se estabelecem entre a composição do leite e a fisiologia do bebê. Eles devem transcender a fronteira biológica em direção ao social, não para estabelecer um elo entre essas duas dimensões, em uma relação de causa efeito, mas sim para tratar dos fenômenos biológicos e fatos sociais que se "hibridizam" naturalmente, em torno das questões que permeiam o leite humano e que terminam por configurar os seus atributos de qualidade (p.23). 
É, pois, considerando esse misto de natureza e cultura que encerra a amamentação, que se devem orientar as ações em prol de sua prática, seja no âmbito individual, seja coletivo. Por se constituir num híbrido, a amamentação implica abordagens que contemplem as informações técnicas referentes aos aspectos biológicos da lactação, e as questões subjetivas da mulher.

\section{A assistência em aleitamento materno}

O cenário da assistência em aleitamento materno descortina um universo multiprofissional, em que a atuação desses diversos atores constituise objeto de pesquisas. Esses estudos revelam que os profissionais de saúde têm considerado a amamentação como um ato puramente instintivo e biológico.

Segundo Silva ${ }^{35}$, o profissional de saúde orienta suas ações de incentivo ao aleitamento entendendo esse fenômeno como um ato natural, decorrente do instinto materno, apesar de reconhecer que esse processo é determinado por objetos sociais do contexto materno.

Nakano ${ }^{25}$, estudando as vivências de amamentação por um grupo de mulheres, fez a seguinte observação sobre o cotidiano dos profissionais de saúde na assistência à amamentação:

Focalizando seu quadro de referência no biológico individual, reforça a representação do fenômeno saúde/doença de forma positivista, desconsiderando os condicionantes histórico-sociais que marcam definitivamente os modos de perceber as situações apresentadas na amamentação, além de desconhecer todos os aspectos sociais envolvidos tanto na definição como na prática relativa aos cuidados realizados (p.108).

Segundo Arantes ${ }^{21}$, as mulheres procuram o profissional para solucionar os seus problemas relativos à vivência da amamentação, mas o discurso que ouvem é baseado em normas e regras que não condizem com as suas reais necessidades, levando-as a sentimentos de medo e insegurança. A autora observa que, no cotidiano da assistência em amamentação, é necessário sair do ideal e contemplar o real na abordagem com a mulher, sendo importante promover reflexões junto a ela, na tentativa de apreender suas razões e motivações. Observação semelhante fazem Ramos \& Almeida ${ }^{14}$, que as mulheres reclamam a falta de apoio; porém, apesar de os profissionais perceberem e reconhecerem os anseios da mulher, eles não são capazes de romper com o modelo em vigor. Esses autores propõem o desenvolvimento de um trabalho dirigido à mulher, com o propósito de prepará-la para o parto, puerpério e amamentação, contemplando as questões a ela subjetivas, numa dimensão psicoprofilática.

No ambiente hospitalar, Souza ${ }^{36}$ observou que a mulher vê-se numa situação de cobrança. A equipe de assistência no pós-parto, no alojamento conjunto, espera dela sucesso no cuidado do seu filho e um bom desempenho no estabelecimento da lactação, e tudo isso em um tempo cronológico imposto pela rotina hospitalar, que nem sempre condiz com o seu próprio tempo.

Leite et al. ${ }^{37}$ chamam a atenção sobre a dinâmica da assistência em amamentação: "[...] é necessário, antes de mais nada, procurarmos entender o universo da mulher na sua individualidade para que, dessa forma, talvez possamos fazer uso fidedigno das articulações dos conhecimentos do campo biológico com os aspectos sociais para apoiá-la no processo de amamentação" (p.159).

Concernente ao nutricionista, apesar da escassez de estudos sobre a sua atuação na assistência em amamentação, esta parece não diferir do encontrado para os demais profissionais que atuam em prol da amamentação.

Monteiro ${ }^{38}$ estudou a representação dos docentes e graduandos dos cursos de Nutrição acerca da amamentação. Esse estudo indicou que a abordagem do tema na Nutrição é insuficiente, uma vez que não instrumentaliza o aluno para atuar de forma que considere os aspectos socioculturais próprios do contexto de vida da nutriz. 
Estudos sobre a atuação do nutricionista na orientação nutricional, revelam que a práxis acadêmica da Nutrição, centrada no biológico, tem reflexo na atuação profissional de seus egressos, limitando sua capacidade para lidar com os aspectos socioculturais.

A atividade de orientação nutricional, na maioria das vezes, é marcada pela dificuldade dos profissionais de penetrarem nas dimensões simbólicas e culturais envolvidas nas questões alimentares ${ }^{39}$. Observação semelhante foi realizada por Amorim et al. ${ }^{40}$, em estudo desenvolvido com o propósito de conhecer a percepção de pediatras e nutricionistas sobre sua formação e sobre a contribuição desta no trato com a clientela. Os autores constataram uma inabilidade desses profissionais de atuar junto à sua clientela numa visão holística, e concluíram que isso ocorre em virtude do processo de formação acadêmica, em que predomina o modelo biológico cartesiano. Bosii ${ }^{41}$ reforça esta análise: [...] a Nutrição desnuda-se do seu caráter social, na medida em que o discurso dominante vai se ocupar do estudo da nutrição a partir do momento da ingestão, ou seja, da relação do alimento em si com o organismo, sem considerar que esta ingestão tem antecedentes fundamentalmente sociais [...] (p.51).

Essa concepção biológica no campo do saber e das práticas da Nutrição no Brasil tem sua raiz no processo de surgimento dos cursos de Nutrição no País. O campo da Nutrição foi constituído por duas correntes bem definidas e distintas do saber médico ${ }^{42}$ : uma voltada para o indivíduo em sua dimensão clínica e a outra para o coletivo, com suas respectivas dinâmicas sociais. A dimensão clínica deu origem à Nutrição Clínica ou Dietoterapia, direcionada para a prática de ações de caráter individual, centradas no "alimento como agente de tratamento", bem como originou a "Nutrição Básica e Fundamental" voltada ao desenvolvimento de pesquisas básicas de caráter experimental e laboratorial. Essa corrente se preocupava, essencialmente, com aspectos clínico - fisiológicos relacionados ao consumo e à utilização dos nutrientes. A outra corrente se instalava na perspectiva social, preocupada, particularmente, com aspectos relacionados à produção, à distribuição e ao consumo de alimentos pela população brasileira, que deu origem à "Alimentação Coletiva" e à "Nutrição Social". Vale acrescentar a análise de Lima ${ }^{43}$, segundo a qual a ciência da nutrição foi concebida constituindo-se a dietética seu núcleo de identidade.

A Nutrição no Brasil, portanto, tem seu lastro histórico delineado pelo modelo biomédico, o que, conseqüentemente, condiciona a prática profissional a uma abordagem reducionista na atenção à alimentação e, mais especificamente, na atenção à amamentação que representa um universo mais amplo de peculiaridades emocionais e sociais da mulher.

A amamentação, um processo alimentar que oferta alimento nutricionalmente completo para o bebê, constitui-se num fenômeno complexo, no qual estão envolvidos aspectos biológicos, psicológicos e sociais, estando intimamente associado à cultura ${ }^{16,21,44}$. Assim, torna-se imperativo ao nutricionista atuar numa visão holística, ou seja, considerando toda a complexidade que envolve a prática da amamentação. Tal proposta coadunase com as Diretrizes Curriculares para os cursos de graduação em Nutrição, especificamente no item XVII do Art. $4^{\circ}$, que trata das competências e habilidades deste profissional: "investigar e aplicar conhecimentos com visão holística do ser humano, integrando equipes multiprofissionais" 45 (p.39).

\section{CONSIDERAÇÕ ES FIN AIS}

Os estudos realizados com o intuito de conhecer a percepção da mulher-mãe-lactante sobre a prática da amamentação mostram a complexidade desse ato, uma vez que envolve uma série de fatores, principalmente, psicossociais.

Orientar para a amamentação é um grande desafio para o profissional de saúde, uma vez que ele se depara com uma demanda para a qual não foi preparado, e que exige sensibilidade e habilidade no seu trato. 
Evidencia-se, portanto, a necessidade da capacitação do profissional de saúde para atuar na assistência em amamentação numa abordagem que ultrapasse as fronteiras do biológico, compreendendo a nutriz em todas as suas dimensões do ser mulher.

Da mesma forma, urge que se amplie o debate, ainda escasso, sobre a atuação do nutricionista na assistência à amamentação, visando a potencializar seu desempenho na orientação dessa prática.

\section{REFER Ê NCIAS}

1. World Health Organization. The optimal duration of exclusive breastfeeding. Results of a WHO systematic review. Note for the press 7 [on line] 2001 April 2: 1-6. Available from: http://www.who. int/inf-pr-2001/en/note2001-07.html

2. Brasil. Ministério da Saúde. Secretaria de Políticas Públicas de Saúde. Guia alimentar para crianças menores de 2 anos. Brasília: Ministério da Saúde; 2002.

3. Akré J. Alimentação infantil: bases fisiológicas. 2a. ed. São Paulo: IBFAN; 1997.

4. World Health Organization. Global strategy for infant and young child feeding. In: 54th World Health Assembly; 2001 may 1; Geneva. p1-4. World Health Organization (WHA54/Inf.Doc./4).

5. Susin LRO, Giugliani ERJ, Kummer SC, Maciel M, Benjamim ACW, Machado DB, et al. Uma estratégia simples que aumenta os conhecimentos das mães em aleitamento materno e melhora as taxas de amamentação. J Pediatr. (Rio J.) 1998; 74(5): 368-76.

6. Bracco NH, Taddei JAAC. Mudança de conhecimento de gestantes em aleitamento materno através de atividade educacional. Rev Paul Pediatr. 2000; 18(1):7-14.

7. Souza LMBM. Promoção, proteção e apoio. Apoio? Representações sociais em aleitamento materno [dissertação]. Rio de Janeiro: Instituto Fernandes Figueira, Fundação Oswaldo Cruz; 1996.

8. Organização Mundial da Saúde. Uma declaração conjunta OMS/UNICEF - proteção, promoção e apoio ao aleitamento materno: o papel especial dos serviços materno-infantis. Genebra; 1989.

9. World Health Organization. Infant and young child nutrition. In: 55th World Health Assembly; 2002 April 16; Geneva. p1-21. World Health Organization (WHA55/15).
10. Rea MF. Reflexões sobre a amamentação no Brasil: de como passamos a 10 meses de duração. Cad Saúde Pública. 2003; 19(Supl 1):37-45.

11. Sociedade Civil Bem-Estar Familiar no Brasil. Pesquisa Nacional de Demografia e Saúde. 1996. Rio de Janeiro: IBGE; 1997.

12. Brasil. Ministério da Saúde. Prevalência de aleitamento materno nas capitais brasileiras e no Distrito Federal. Relatório Final. Brasília: Ministério da Saúde; 2000.

13. Sandre-Pereira G, Colares LGT, Carmo MGT, Soares EA. Conhecimentos maternos sobre amamentação entre puérperas inscritas em programa de pré-natal. Cad Saúde Pública. 2000; 16(2):457-66.

14. Ramos CV, Almeida JAG. Alegações maternas para o desmame: estudo qualitativo. J Pediatr. (Rio J.) 2003; 79(5):385-90.

15. Soares NT, Guimarães ARP, Sampaio HAC, Almeida PC, Coelho RR. Padrão alimentar de lactentes residentes em áreas periféricas de Fortaleza. Rev Nutr. 2000; 13 (3):167-76.

16. Rea MF, Cukier R. Razões de desmame e de introdução da mamadeira. Uma abordagem alternativa para seu estudo. Rev Saúde Pública. 1988; 22(3): 184-91.

17. Siqueira R. Reflexões sobre as causas de desmame precoce observadas em dinâmicas de grupo de incentivo ao aleitamento materno. J Pediatr. (Rio J.) 1994; 70(1):16-20.

18. Venâncio SI, Escuder MML, Kitoko P, Rea, MF, Monteiro, CA. Freqüência e determinantes do aleitamento materno em municípios do Estado de São Paulo. Rev Saúde Pública. 2002; 36(3):313-8.

19. Vieira GO, Almeida JAG, Silva LR, Cabral VA, Santana PV. Fatores associados ao aleitamento materno e desmame em Feira de Santana, Bahia. Rev Bras Saúde Mater Infant. 2004; 4(2):143-50.

20. Minayo MCS. O desafio do conhecimento: pesquisa qualitativa em saúde. 4a. ed. São Paulo: Hucitec; 1996.

21. Arantes CLS. Amamentação: visão das mulheres que amamentam. J Pediatr. (Rio J.) 1995; 71(4): 195-202.

22. Adesse L. Amamentação: um ato contraditório [dissertação]. Rio de Janeiro: Instituto Fernandes Figueira, Fundação Oswaldo Cruz; 1994.

23. Moreira KFA. Aleitamento a luz dos direitos reprodutivos da mulher: afinal do que se trata? [dissertação]. Ribeirão Preto: Escola de Enfermagem de Ribeirão Preto, Universidade de São Paulo; 2003.

24. Nakano MAS. O aleitamento materno no cotidiano feminino [dissertação]. Ribeirão Preto: Faculdade 
de Medicina de Ribeirão Preto, Universidade de São Paulo; 1996.

25. Nakano AMS. As vivências da amamentação para um grupo de mulheres: nos limites de ser "o corpo para o filho" e de ser "o corpo para si" [livre docência]. Ribeirão Preto: Faculdade de Medicina de Ribeirão Preto, Universidade de São Paulo; 2003.

26. Badinter E. Um amor conquistado: o mito do amor materno. 3a. ed. Rio de Janeiro: Nova Fronteira; 1985.

27. Silva AAM. Amamentação: fardo ou desejo? Estudo histórico social dos deveres e práticas sobre aleitamento na sociedade brasileira [dissertação]. Ribeirão Preto: Faculdade de Medicina de Ribeirão Preto, Universidade de São Paulo; 1990.

28. Nakano AMS, Mamede MV. A prática do aleitamento materno em um grupo de mulheres brasileiras: movimento de acomodação e resistência. Rev Latino-Am. Enfermagem. 1999; 7(3):69-76.

29. Machado MMTM. A conquista da amamentação: o olhar da mulher [dissertação]. Fortaleza: Universidade Federal do Ceará; 1999.

30. Ichisato SMT, Shimoa AKK. Aleitamento materno e as crenças alimentares. Rev Latino-Am Enfermagem. 2001; 9(5):70-6.

31. Ichisato SMT. Lactogogos e a mulher lactante [dissertação]. Ribeirão Preto: Escola de Enfermagem de Ribeirão Preto, Universidade de São Paulo; 1999.

32. Ramos CV. Amamentação: do discurso à prática - um estudo sobre a percepção de mulheres assistidas na MDER - Teresina - Piauí [dissertação]. Rio de Janeiro: Instituto Fernandes Figueira, Fundação Oswaldo Cruz; 2000.

33. Rezende MA, Sigaud CHS, Veríssimo MDLOR, Chiesa AM, Bertolozzi MR. O processo de comunicação na promoção do aleitamento materno. Rev Latino-Am Enfermagem. 2002; 10(2):234-8.

34. Almeida JAG. Amamentação: um híbrido natureza cultura. Rio de Janeiro: Fiocruz; 1999.
35. Silva IA. Construindo perspectivas sobre a assistência em amamentação: um processo interacional [livre-docência]. São Paulo: Escola de Enfermagem, Universidade de São Paulo; 1999.

36. Souza KS. O dito e o não dito da amamentação: o sentido de mães nutrizes na vivência do alojamento conjunto [dissertação]. Rio de Janeiro: Escola de Enfermagem Anna Nery, Universidade Federal do Rio de Janeiro; 2000.

37. Leite AM, Silva IA, Scochi CGS. Comunicação não-verbal: uma contribuição para o aconselhamento em amamentação. Rev Latino-Am Enfermagem. 2004; 12(2):258-64.

38. Monteiro KAO. O nutricionista e a amamentação: formação e docência para uma prática profissional [dissertação]. Rio de Janeiro: Instituto Fernandes Figueira, Fundação Oswaldo Cruz; 2000.

39. Tonial SR. Desnutrição e obesidade: faces contraditórias na miséria e na abundância [tese]. Rio de Janeiro: Instituto Fernandes Figueira, Fundação Oswaldo Cruz; 2001.

40. Amorim STSP, Moreira H, Carraro TE. A formação de pediatras e nutricionistas: a dimensão humana. Rev Nutr. 2001; 14(2):111-8.

41. Bosi MLMA. A face oculta da nutrição: ciência e ideologia. Rio de Janeiro: UFRJ; 1988.

42. Vasconcelos FAG. O nutricionista no Brasil: uma análise histórica. Rev Nutr. 2002; 15(2):127-38.

43. Lima ES. Gênese e constituição da educação alimentar: a instauração da norma. Hist Ciênc Saúde - Manguinhos. 1998; 5(1):57-83.

44. Araújo LDS. Querer/Poder amamentar: uma questão de representação? Londrina: UEL; 1997.

45. Brasil. Conselho Nacional de Educação. Câmara de Educação Superior. Resolução CNE/CES 5/2001. Diretrizes curriculares nacionais do curso de graduação em nutrição. Diário Oficial da União. 2001; 9 nov.; Seção 1, p.39.

Recebido em: 21/11/2005

Versão final reapresentada em: 30/10/2006 Aprovado em: 22/12/2006 